University of Michigan Law School

University of Michigan Law School Scholarship Repository

Articles

Faculty Scholarship

2003

\title{
Understanding Climatic Impacts, Vulnerabilities, and Adaptation in the United States: Building a Capacity for Assessment
}

Edward A. Parson

University of Michigan Law School, parson@law.ucla.edu

Robert W. Corell

American Meteorological Society

Eric J. Barron

Pennsylvania State University

Virginia Burkett

U.S.G.S. National Wetlands Research Center

Anthony Janetos

World Resources Institute

See next page for additional authors

Follow this and additional works at: https://repository.law.umich.edu/articles

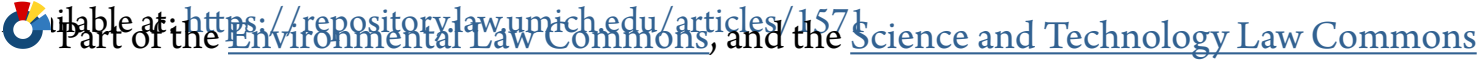

\section{Recommended Citation}

Parson, Edward A. "Understanding Climatic Impacts, Vulnerabilities, and Adaptation in the United States: Building a Capacity for Assessment." R. W. Corell et al., co-authors. Climatic Change 57, no. 1 (2003): 9-42.

This Article is brought to you for free and open access by the Faculty Scholarship at University of Michigan Law School Scholarship Repository. It has been accepted for inclusion in Articles by an authorized administrator of University of Michigan Law School Scholarship Repository. For more information, please contact mlaw.repository@umich.edu. 


\section{Authors}

Edward A. Parson, Robert W. Corell, Eric J. Barron, Virginia Burkett, Anthony Janetos, Linda Joyce, Thomas R. Karl, Michael C. MacCracken, Jerry Melillo, M. Granger Morgan, David S. Schimel, and Thomas Wilbanks 


\title{
UNDERSTANDING CLIMATIC IMPACTS, VULNERABILITIES, AND ADAPTATION IN THE UNITED STATES: BUILDING A CAPACITY FOR ASSESSMENT
}

\author{
EDWARD A. PARSON ${ }^{1}$, ROBERT W. CORELL ${ }^{2}$, ERIC J. BARRON ${ }^{3}$, \\ VIRGINIA BURKETT ${ }^{4}$, ANTHONY JANETOS ${ }^{5}$, LINDA JOYCE $^{6}$, \\ THOMAS R. KARL ${ }^{7}$, MICHAEL C. MACCRACKEN ${ }^{8}$, JERRY MELILLO $^{9}$ \\ M. GRANGER MORGAN ${ }^{10}$, DAVID S. SCHIMEL ${ }^{11}$ and THOMAS WILBANKS ${ }^{12}$ \\ ${ }^{1}$ John F. Kennedy School of Government, Harvard University, 79 JFK St, \\ Cambridge, MA 02138, U.S.A. \\ E-mail: ted_parson@harvard.edu,U.S.A. \\ ${ }^{2}$ American Meteorological Society, U.S.A. \\ ${ }^{3}$ Pennsylvania State University, U.S.A. \\ ${ }^{4}$ U.S.GS National Wetlands Research Center, U.S.A. \\ ${ }^{5}$ World Resources Institute, U.S.A. \\ ${ }^{6}$ U.S.DA Forest Service, U.S.A. \\ ${ }^{7}$ NOAA National Climatic Data Center, U.S.A. \\ ${ }^{8}$ U.S. Global Change Research Program and Lawrence Livermore National Laboratory, U.S.A. \\ ${ }^{9}$ Ecosystems Center, Marine Biological Laboratory, U.S.A. \\ ${ }^{10}$ Carnegie-Mellon University, U.S.A. \\ ${ }^{11}$ Max-Planck Institute for Biogeochemistry and National Center for Atmospheric Research, U.S.A. \\ ${ }^{12}$ Oak Ridge National Laboratory, U.S.A.
}

\begin{abstract}
Based on the experience of the U.S. National Assessment, we propose a program of research and analysis to advance capability for assessment of climate impacts, vulnerabilities, and adaptation options. We identify specific priorities for scientific research on the responses of ecological and socioeconomic systems to climate and other stresses; for improvement in the climatic inputs to impact assessments; and for further development of assessment methods to improve their practical utility to decision-makers. Finally, we propose a new institutional model for assessment, based principally on regional efforts that integrate observations, research, data, applications, and assessment on climate and linked environmental-change issues. The proposed program will require effective collaboration between scientists, resource managers, and other stakeholders, all of whose expertise is needed to define and prioritize key regional issues, characterize relevant uncertainties, and assess potential responses. While both scientifically and organizationally challenging, such an integrated program holds the best promise of advancing our capacity to manage resources and the economy adaptively under a changing climate.
\end{abstract}

The U.S. National Assessment of Potential Consequences of Climate Variability and Change has recently been completed (NAST 2000, 2001). Conducted between 1997 and 2001, in parallel with the IPCC's assessment of climate impacts worldwide (IPCC, 2001b) and several other assessments at national or global scale (e.g., UKCIP, 2000; Parry and Livermore, 1999; Maxwell et al., 1997), the assessment 
examined climate-related impacts and vulnerabilities in the United States. It drew on workshops of experts and stakeholders held in 19 U.S. regions, followed by indepth study by separate analytic teams organized in a matrix structure. These teams examined impacts in nine major sub-national regions and five sectors of national importance (agriculture, water, human health, coastal areas and marine resources, and forests). For each region and sector, and in a synthesis for the nation as a whole, the assessment sought to address the most important questions about climate and its impacts: What will the major effects of climate change be? How serious are they? Where do key vulnerabilities and opportunities lie? What adaptation strategies can help minimize losses and take maximum advantage of benefits? What determines the ability of natural and human systems to adapt to change? And how will climate change interact with other stresses?

Assessment teams used various methods - including synthesis of existing scientific knowledge, observed sensitivity to climate variability and extremes over the 20th century, model-based projections, and expert judgment - to describe and, where possible, quantify potential impacts over two time horizons, 2-3 decades and one century. Projections used two climate-model scenarios, both driven by the same scenario of global greenhouse-gas emissions over the 21 st century. ${ }^{\star}$ Three socio-economic scenarios were also used, reflecting a range of possible trends for U.S. population and economic growth. In view of the level of sub-national detail examined, the use of multiple climate and socio-economic scenarios, and the consistent examination of impacts of both climatic variability and projected 21st-century trends, the National Assessment has been the most ambitious attempt to date to assess potential climate impacts. It made significant progress in understanding climate-related impacts and vulnerabilities for the United States. ${ }^{\star \star}$

The National Assessment also identified many limitations to present knowledge and skill - including scientific uncertainties, inadequacies of data, needs for integration of existing information, and weaknesses of assessment methods - that constrained its ability to answer the questions with which it was charged. This paper complements the assessment's official publications by focusing on what the assessment was not able to do, identifying the key limitations of knowledge and skill that the assessment's work revealed. These provide the guideposts for a program of research, analysis, and methods development to advance our assessment capacity and provide more useful insights to inform policy and decisions. Although we concentrate on the needs of U.S. assessments, those we identify are broadly shared by all recent assessments. The program we outline here, like the assessment

^ The two primary climate models used were from the UK's Hadley Centre (Mitchell et al., 1995; Johns et al., 1997) and the Canadian Centre for Climate Modeling and Analysis (Boer et al., 1999a,b). These two model's projections lie near the low and high end respectively of the range of current projections (IPCC, 2001a). Both were driven by emissions scenario IS92a, the IPCC's middle scenario published in 1992. This scenario remains near the middle of the range of the IPCC's recent update of emission scenarios (IPCC 2000, 2001a).

$\star \star$ Full reports for each region and sector, and workshop reports, are available at www.usgcrp.gov. 
itself, concerns climate impacts and associated questions of adaptation and vulnerability. It is not a complete global change research program. Nor does it address all areas of work needed to inform a rational response to climate change, which will also require an expanded program of research and development in technologies for mitigation and an enhanced capacity for integrated assessment of climate change mitigation and adaptation (PCAST, 1997).

To assess climate impacts, they must be defined. The National Assessment and other recent assessments have adopted very similar definitions: a climate impact is the change caused by a projected change in climate, measured relative to a continuation of present climatic conditions. While seemingly simple, this concept embeds deep difficulties that have limited the power and utility of impact assessments despite recent increases in their number, scale, and sophistication. Three difficulties are especially prominent: complex causal linkages between impacts, vulnerability, and adaptation; linkages between multiple domains of climate impact at various spatial scales; and multiple stresses, environmental and other, that are occurring with climate change.

A standard framework for understanding the linked concepts of impact, adaptation, and vulnerability has been widely employed by the IPCC and other assessments. This framework distinguishes the initial or first-order impact on a system resulting from a specified exposure to climatic change, from the residual or net impact that remains following adaptation to the climate change. Adaptations can occur autonomously in both biological and human systems to modulate or dampen the initial impact. In addition, in human systems, governmental or nongovernmental decision-makers can make intentional adaptations, either in advance of a projected climate change or in response to a realized one. A community, region, or sector is vulnerable to climate or other stresses if these have a high probability of causing severe adverse consequences, such as injuries or deaths, loss of property, infrastructure, or livelihoods, forced migrations, etc. (Kates et al., 1985; Smit et al., 1999, 2000; Kane and Yohe, 2000).

This framework grants a conceptual coherence to impact studies, but several complexities obstruct its practical application. The concepts of exposure, sensitivity, adaptation, and vulnerability must all be defined relative to multiple dimensions of climate: changes and rates of change in multiple climate variables (temperature, humidity, and precipitation), in their mean values, variability, and extreme values. Both impacts and adaptation may depend as strongly on rates of change as on their magnitudes, since any specified change will usually (but not always) bring more severe impacts if it happens more rapidly. Moreover, the response that we observe of any system to a climatic change or event is typically a combination of initial impacts and adaptive response. Since sensitivity and adaptation may be determined by totally different factors but impossible to observe separately, observed responses to past climate variability or extremes may be highly misleading predictors of future responses. 
A second class of challenges to climate impact assessment arises from linkages between impacts in different domains, locations, and spatial scales. Impacts on one system can modify impacts on others, through both biophysical and socioeconomic processes. For example, climatic impacts on a region's agriculture and its freshwater resources can influence each other in multiple ways. While a few studies have taken preliminary steps toward integrated assessment of multiple climate impacts (e.g., Rosenberg and Crosson, 1993), separate assessments of sectoral impacts - which are at best aggregated, not integrated - remain the norm. Similarly, impacts can differ strongly with the spatial scale at which they are described, and impacts in any location will reflect the interaction of biophysical and socio-economic processes operating at multiple scales, from the local to the global. Consequently, impacts in any location may be acutely sensitive to how the location is defined, and may depend strongly on climate impacts or other processes operating elsewhere, e.g., through effects on agricultural markets, capital flows, or migration. Capturing such cross-impact effects will require methods analogous to economic input-output analysis, but subsuming a broader set of both socio-economic and biophysical dependencies.

A third class of difficulties concerns linkages between climate impacts and other stresses. Climate change is not occurring and will not occur in isolation, but in conjunction with many other forms of both environmental and non-environmental change. Linked human activities and natural processes are simultaneously altering the global cycles of water, carbon, nitrogen, phosphorus, and sulfur, the radiative properties and chemical composition of the atmosphere, the physical structure of land cover over large scales, the chemistry and biology of freshwaters and oceans, and more (Vitousek et al., 1997). These multiple stresses interact in complex ways, in both their biophysical aspects and their linkages to human impacts and responses. Some systems' responses to climate may interact so strongly with nonclimatic stresses that an assessment of the climatic response alone - in effect, the partial derivative with respect to climate - may be highly misleading. Multiple stresses pose sharp problems both for constructing useful scenarios of change and for analyzing systems' responses to change.

These challenges define the long-term agenda for working to understand climate impacts, but our experience in the National Assessment also identified many more immediate needs. In this paper, we map out a program of work to advance assessment capability incrementally while keeping the longer-term challenges in view. This program should be viewed adaptively: the directions we identify should be pursued, progress periodically evaluated, and priorities adapted based on new knowledge gained, developing capabilities, and evolving decision needs. The program addresses needs for both knowledge and skill, grouped into four elements.

The first two elements are research on the climatic responses of ecological and socio-economic systems. Research on ecosystem responses should consider both managed and unmanaged systems, and their interactions with human land-use and management decisions. Research on climatic responses of socio-economic sys- 
tems should include study of key vulnerabilities and their socio-economic causes, and both empirical study and prospective analysis of adaptation measures to reduce vulnerabilities. These two elements represent a major shift in priority, from further refinement of climate projections toward study of the responses of climatesensitive systems: if climate changes in this or that way, what will be the effects on ecosystems, valued resources, and communities, and what can be done about it.

Only partly counter-balancing this shift of priority, the third element identifies a set of activities to improve the climatic inputs to assessments. These are not principally research questions in climate science, but rather stress the integration and provision of climate-related information to support better impact assessment. They include more extensive climate-model replications to better characterize model-related uncertainty, climate variability, and the effects of alternative emission futures; improved data on past climate variability and change, with associated forcings and impacts; and improved production, maintenance, and usability of climatic and related data. The fourth element targets the crucial distinctions between assessment and the scientific research on which it draws, identifying priorities for development of assessment methods to improve their practical utility to decisionmakers. After summarizing the priority directions of work that we recommend, the final section proposes a new institutional model for assessment, based principally on regional efforts that integrate observations, research, data, applications, and assessment on climate and linked environmental-change issues.

\section{Element 1: Responses of Ecological Systems}

Recent progress has significantly improved understanding of the climate system and projections of future climate change. In contrast, research on the responses of ecological and societal systems to climate change and other environmental stresses is crucially needed but has been relatively neglected (NRC, 1999b). Advancing understanding of these systems' climatic responses is the first priority for improving assessments of climate impacts and vulnerabilities.

\subsection{RESPONSES OF TERRESTRIAL AND AQUATIC ECOSYSTEMS}

Ecosystems respond to changes in climate, $\mathrm{CO}_{2}$, and other stresses at multiple time and space scales. Individual plant and animal species respond through changes in fecundity, establishment and survival, growth, death, and rates of migration or dispersal. In turn, these changes alter patterns of competition, predation, and other inter-species interactions (plant-animal-microbial), as well as the prevailing patterns of disturbances such as fire and insect outbreaks. These ecosystem effects now represent critical uncertainties in understanding climate and its impacts, both because natural ecosystems are likely to be more vulnerable to climate changes than more intensively managed systems - a finding common to several recent 
assessments - and because ecosystem feedbacks may alter the magnitude and character of environmental change.

Some elements of these responses are relatively well known. For example, many experimental and process-based studies have examined responses of individual plant species to elevated atmospheric $\mathrm{CO}_{2}$, while field studies and process-based models have provided insights into direct effects of climate on some species and ecosystems. Tolerance to variation in temperature and precipitation is relatively well known for many terrestrial plant species, especially trees (Woodward, 1987), but effects on animal species (both vertebrates and invertebrates) and on aquatic and marine species (for which related changes in water level and quality, tidal regimes, and salinity must also be considered) are much less well known.

Ecosystem responses to climate and associated changes will depend on the abilities of organisms to disperse or migrate as their optimal range moves. For plants, migration ability depends on fine-scale processes such as seed production, germination, and seedling establishment, all strongly influenced by climate. As plant species migrate at different rates and compete for resources such as light, water, and nutrients, relative advantages will shift among them and the structure of communities will change, reflecting complex interactions between species' characteristics, genetic variation and density, plant-microbe interactions such as nitrogen fixation, and the characteristics and diversity of herbivores, pathogens, and pollinators. Ranges of mutually dependent species may diverge, as different migration rates or barriers separate predator from prey, grazer from producer, or pollinator from pollinated species. Patterns of the frequency, intensity, and distribution of disturbances such as fire, drought, insects, and disease will be altered by climate change and will both influence and be influenced by these changes in community structure and species mix. In addition to its direct effects on insect and disease life cycles, climate change could induce changes in the vulnerability of host species by altering their physiology or production of chemical defenses, or could alter the ecological mechanisms that trigger outbreaks of insects or disease (Lincoln et al., 1993; Ayres and Lombardero, 2000). While gradual climate change may allow gradual replacement of species in landscapes, disturbances could trigger abrupt transitions as regrowth is determined by interactions between old species under increasing climatic stress and species dispersing into newly advantageous ranges. Invasive species (e.g., kudzu in the southeastern states, mile-a-minute in the Northeast and mid-Atlantic, and yellow star thistle in the western states) represent additional perturbations to existing communities, which can interact with changing climate and further modify disturbance regimes (Mack and D'Antonio, 1998; Duke and Mooney, 1999). The evolving dynamics of interdependent plant, animal, and microbial communities will regulate ecosystems' diversity and functioning (e.g., nutrient cycling, carbon storage), and the valued goods and services they provide (Körner et al., 1996; Sala et al., 1999).

To date, most studies of changed $\mathrm{CO}_{2}$ concentration and climate have examined only small parts of these complex ecosystem dynamics - e.g., effects on 
single species, single plant-insect relationships, or plant communities only. Some specific responses of ecosystems and species are strongly enough linked to potentially important impacts to merit additional focused studies. For example, studies are needed of climate and $\mathrm{CO}_{2}$ effects on certain plant species whose secondary metabolites make them valued or noxious, e.g., production of medicines from belladonna and foxglove (digitalis), production of allergens from ragweed and poison ivy, and production of intoxicants or narcotics from opium, coca, and marijuana. These effects can be large: e.g., one recent study found that ragweed's pollen production doubled when $\mathrm{CO}_{2}$ concentration was elevated from 19th-century to present levels (270 to $360 \mathrm{ppm}$ ), and doubled again with a further increase to 600 ppm (Ziska and Caulfield, 2000). Similarly, advancing understanding of climate effects on human health will require focused studies of specific causal pathways whose potential health impact is large. These include, for example, studies of the effects of weather, climate, and $\mathrm{CO}_{2}$ on host species such as vectors (insects and ticks), rodents, birds, and deer, as well as the pathogens they carry; studies of links between climate, pollutant runoff, marine ecology and toxic algae; and studies of the effects of rainfall and snowmelt, including extreme events, on the fate and transport of microbial pathogens.

Advancing understanding of ecosystem impacts and responses will also require studies that address broader interactions at multiple scales, including a combination of basic process studies, empirical studies, quantitative modeling, and experimental manipulation of ecosystems. Paleoecological data have provided some general estimates of species migration rates, while many empirical studies have examined climatic correlates of the range, reproduction, and outbreak dynamics of some important forest insects and diseases. Further observation of both the paleo record and contemporary systems is needed to estimate future rates, identify limits to migration including the effects of human barriers and landscape alteration, and identify particularly vulnerable species and management options.

Gaining further insights into linked changes in community structure and disturbance regimes will require further development of process-based ecosystem models. Present models largely assume successful migration of all species, so community structures undergo no major changes and present ecosystems remain intact as they follow their climatically optimal zones. In reality, associated species are likely to migrate at very different rates, some too slowly to keep up with the climate. Under these conditions, existing ecosystems will not be transported but will be torn apart, and new communities and ecosystems continually re-assembled (Cramer et al., 1999). Little is known about the likely structure of such new and transient ecosystems, or their implications for productivity, nutrient cycling, or ecosystem services. While some dynamic ecosystem models now include representations of fire and drought, little modeling has been done of other disturbances, their ecosystem consequences, or their interactions with changed climate and $\mathrm{CO}_{2}$ concentration (Volney, 1996). 
Better understanding of the effects of these linked changes will also require experimental manipulation of ecosystems. While many experiments have examined $\mathrm{CO}_{2}$ and temperature effects on individual species or simple systems, there has not yet been adequate study of even the effect of elevated $\mathrm{CO}_{2}$ on mature trees; or of responses of even simple systems to multiple stresses; or of ecosystem responses at the required range of spatial scales. Consequently, even for the most intensively studied effects, those of elevated $\mathrm{CO}_{2}$ on photosynthesis and water use efficiency, major uncertainties remain about their scaling, their persistence, their variation across ecosystem types, and their implications for ecosystem function and possible climate feedbacks, such as possible accelerated carbon release from tundra, wetland or boreal soils under warming.

Learning more about interactive effects of multiple stresses on realistic ecosystems will require experimental manipulations of ecosystems on a larger scale than yet conducted. Some manipulations, e.g., those involving $\mathrm{CO}_{2}$, precipitation and nutrients, can be done in field settings. Others, particularly those involving temperature manipulations, will require ecosystem enclosures. For large-stature ecosystems such as forests, which are critical for understanding the global carbon cycle, the enclosures will need to be large, on the scale of Biosphere II. Examining responses to multiple stresses will require factorial experiments that manipulate multiple characteristics (e.g., temperature, $\mathrm{CO}_{2}$ concentration, precipitation, and nutrient levels) alone and in various combinations, ideally requiring several such large-scale enclosures.

\subsection{ECOLOGICAL RESPONSES OF MANAGED SYSTEMS}

Ecosystems under intensive human management such as agriculture and managed forests also show substantial sensitivity to climate, but are dominated by management decisions that control the species and cultivars planted, nutrients added, methods of pest control used, and technologies employed. The responses of these systems to climate are likely to differ strongly from those of less managed ecosystems. Key research questions include the following. How will the growth, food production, and other characteristics (e.g., water use, nutrient cycling, fecundity) of important crop species change under projected changes in $\mathrm{CO}_{2}$ and climate, including changes in variability and extremes? How will other species that interact strongly with crops, such as weeds, pests, and diseases, respond to the same changes? How are these responses modified by other environmental stresses such as nitrogen and sulfur deposition, oxidizing air pollution, changes in soil properties, and invasive species? What are the implications of these effects for the productivity and profitability of agriculture and forestry, for management practices, and for interactions between management and environmental change? Recent agricultural analyses in the National Assessment and elsewhere illustrate the magnitude of the research challenge: large productivity gains are projected for some crops from elevated $\mathrm{CO}_{2}$ and climate change, but the effects of potential changes in precip- 
itation extremes, weeds, pests, and diseases, which could exceed the direct effects of climate and $\mathrm{CO}_{2}$, are not yet considered.

The $\mathrm{CO}_{2}$ response of several hundred plant species has been studied, including many important crop species. In general plants grow faster in elevated $\mathrm{CO}_{2}$, due to effects on both photosynthetic efficiency and water-use efficiency. Plants with C3 photosynthesis (e.g., rice, soybeans, cotton, peanuts) generally show a stronger response, $\mathrm{C} 4$ plants (e.g., corn, sugar cane, sorghum) a weaker one, but responses vary widely among species and even among cultivars of the same species. For most crop species, however, only one or a few cultivars have been studied. Studies of multiple cultivars are needed to assess which ones will be most advantaged under higher $\mathrm{CO}_{2}$, and to assess how much robustness to changed conditions is provided by present agronomic genetic diversity.

A realistic understanding of agricultural impacts will also require studying effects on multiple crop characteristics, not just productivity and seed yield. Modelbased studies must consider climate variability, especially the seasonal and weather extreme events that strongly affect agricultural production. Experimental studies must consider changes in plant structure, fecundity, and resistance to water extremes, pests, and diseases, over the crop's entire life cycle. Several potentially important changes in crop characteristics under warmer temperatures have been identified, such as decline in grain quality and floral sterility in rice (e.g., Conroy et al., 1994; Ziska and Manalo, 1996). Various synergistic effects between $\mathrm{CO}_{2}$ and warming have also been identified, including short-term enhancement of photosynthesis and enhanced plant canopy warming due to reduced transpirational cooling (Matsui et al., 1997). These and related effects need further study in field experiments, and these processes must be integrated into crop models to obtain more realistic projections of agricultural impacts.

Weeds, like crops, have a wide genetic base and will likely show diverse responses to changed climate and $\mathrm{CO}_{2}$. Initial experiments have found that a few major weed species respond more strongly to $\mathrm{CO}_{2}$ than crops do (Patterson, 1995; Ziska and Bunce, 1997), and that crop-yield losses due to weeds increase under elevated $\mathrm{CO}_{2}$ (Ziska, 2000), but the interactions are complex. For example, elevated $\mathrm{CO}_{2}$ favors rice in competition with a $\mathrm{C} 4$ weed, but raising temperature as well as $\mathrm{CO}_{2}$ shifts the advantage to the weed (Alberto et al., 1996). Increased $\mathrm{CO}_{2}$ also increases herbicide tolerance in some weeds (Ziska and Teasdale, 2000). The range, outbreak dynamics, and behavior of pest and disease species are also likely to respond to climate change, both directly and indirectly (Patterson et al., 1999). Realistic assessment of climate impacts on agricultural productivity and management will require further experimental studies in field conditions of responses of major weed, pest, and disease species, and their interactions with crops, under projected changes in climate, $\mathrm{CO}_{2}$ concentration, and other environmental conditions.

For managed forests, even basic studies of the direct effects of enhanced $\mathrm{CO}_{2}$ concentration and changing climate have been done for only a few tree species, none in mature forests. Present ecosystem models can project total growth rates 
and canopy development under changed climate but do not yet represent carbon allocation well enough to provide useful projections of stemwood production, which is critical for assessing climate impacts on forests that are managed for wood production or carbon sequestration (Gregory et al., 1999). In addition, little is known about how changed climate and $\mathrm{CO}_{2}$ will affect seed production, germination, and seedling establishment, and consequently the ability of forests to regenerate after harvest. Studies of these processes are needed that consider diverse forest types, as well as differences in water and nutrient availability that arise from diverse topography and soil conditions.

\subsection{INTERACTIONS OF ECOSYSTEM EFFECTS WITH LAND USE AND MANAGEMENT}

The ecosystem models used in the National Assessment projected the characteristics of potential natural vegetation, i.e., that which would be present absent human intervention. Other analyses of ecological changes consider human land-use, but treat it statically. Most land, however, is subject to varying degrees of human management, including the possibility of large-scale conversion in response to environmental, demographic, or economic factors. Land use and management can alter the quantity, quality, and spatial arrangement of habitats across the landscape, and can strongly affect the vulnerability of systems to environmental change, by altering productivity, nutrient cycling, retention and cycling of water, disturbance regimes, and species' ability to disperse and migrate. Land use and management consequently shape vulnerability to climate and other changes, and can provide powerful tools to adapt to change.

The treatment of land use and management in current ecosystem models is at best preliminary. Better understanding of ecosystem-land use interactions will require both empirical studies and models that consider the joint effects of climate, land use, and other environmental stresses on species dynamics and ecosystem structure and function. While developing an integrated ability to model ecosystem responses to human management and environmental change is a long-term project, certain directions are promising in the near term. These include, for example, using current land-cover data to specify starting conditions in dynamic vegetation models, or allowing exogenous specification of large-scale management decisions such as harvest or planting decisions in forests, or crop choice and nutrient application in agriculture. Even these developments would allow a wide range of analyses of ecosystem sensitivity to land-use change and management decisions. A more challenging and long-term project will be to extend ecosystem models with endogenous modeling of the environmental, economic, and social factors determining land-use conversion and management decisions.

Effects of land-use and management on water quality under climate change also need further examination, in particular the possibility of climate-related changes in agricultural pesticide use and subsequent effects on water quality and the status of 
river, estuary, and coastal ecosystems. Agricultural studies in the National Assessment considered increased application and runoff of fertilizers and pesticides due to higher precipitation and longer growing seasons, but these increases have not yet been linked to impacts on water quality or coastal ecosystems. Moreover, the potential for still larger increases in chemical use arising from changes in nutrient needs, or the range and characteristics of weeds or pests, have not yet been studied.

\section{Element 2: Adaptation and Vulnerability of Social Systems}

\subsection{SOCIAL AND ECONOMIC VULNERABILITIES}

The National Assessment, like other recent assessments, identified many potential sources of vulnerability to climate change that require further analysis. For example, coastal cities and infrastructure face vulnerability to climate-driven changes in sea level, storms, storm surge, erosion, and flooding. Interactions between specific patterns of coastal development (e.g., density, location, building type, infrastructure, and technology) and specific scenarios of change in the frequency, intensity, and spatial distribution of extreme events, need further study. So do potential over-loading and reduced reliability of electric power systems under simultaneous pressure from institutional and policy failures, extreme weather events, increased peak demand from hotter and more humid summers - and for hydroelectric systems, climate-related changes in hydrological regimes. Tight couplings between multiple aspects of urban life may generate surprising emergent patterns of vulnerability, such as secondary consequences of disruptions to electrical power, transport, or other forms of infrastructure. Movement of people, goods, services, and information create linkages between cities and remote locations, potentially causing impacts and patterns of vulnerability to propagate over long distances through effects on markets, migration, or communication. These vulnerabilities may have patterns of fine-scale variation across locations or groups. But while present assessments have identified many such potential vulnerabilities, these lists at present are predominantly judgmental or arbitrary.

Further analysis of specific causal pathways is needed to prioritize vulnerabilities, identify recurring patterns, and pursue general understanding. Modes of analysis analogous to event-tree and fault-tree analysis in engineered systems offer promising approaches. In addition, the more general conditions that determine adaptive capacity of particular communities, institutions, and resources, and hence their vulnerability to diverse stresses, need further study (Downing et al., 2000; Ribot, 1995; Ribot et al., 1996; Cutter, 1996; G. E. Clark et al., 1998). Although extensive studies of local and regional vulnerabilities have been conducted in other contexts (e.g., food security, natural hazards), theoretical understanding of the determinants of vulnerability remains limited and work to integrate existing knowledge of vulnerability with studies of projected climate change has only begun 
(see, e.g., Bohle et al., 1994; W. C. Clark et al., 2000; Kasperson et al., 1995). Key research questions include the following. What social and institutional factors enhance or constrain capacity for adaptation, and how can it be increased? How important a factor in shaping adaptability is wealth, including its sources and distribution? How do institutions, social networks, and entitlements contribute to adaptive capacity and interact with wealth (Sen, 1990; Miller et al., 1997; Adger and Kelly, 1999; Kelly and Adger, 2000)? Are there characteristic ways that specific technologies or policies expand or limit adaptability? How does the history of climate variability in a place affect adaptability to trends and to variability outside the historic range? The concept of syndromes of multiple linked environmental, economic and social factors that strongly shape vulnerability suggests one promising approach to structuring such study (Petschel-Held et al., 1999).

\subsection{EMPIRICAL STUDIES OF PAST ADAPTATION}

Capacity for adaptation is an important determinant of climate impacts in managed resources and socio-economic systems, but limited understanding of adaptive capacity presently limits assessments' ability to identify the most acute vulnerabilities (UNEP, 1998; Smit et al., 1999). Impact assessments have typically adopted simple, extreme assumptions about decision-makers' responses to observed and projected climate: either they do not adapt at all, or they adapt optimally - by adopting selected options from a specified list, or by optimally adjusting some continuous response such as irrigation application or the height of coastal barriers (see, e.g., Easterling et al., 1993; Rosenzweig and Parry, 1994; Reilly et al., 1994; Mendelsohn et al., 1994). These studies provide wide upper and lower bounds on likely impacts, and demonstrate that the potential of adaptation to mitigate most impacts is large. But they offer little insight into what adaptation is likely actually to occur, the conditions that influence it, or its effectiveness (Tol et al., 1998; Risbey et al., 1999; Schneider et al., 2000). Better understanding of these questions will require both theoretical and empirical studies: better theoretical frameworks to understand how decision-makers process information about climatic risks, identify and assess adaptation options, and choose whether, when, and how to employ them; and empirical studies of how decision-makers and institutions in climate-sensitive sectors have adapted in the past to climate variability, change, and extreme events (NRC, 1999c; Tol et al., 1999).

An increasing body of studies has examined specific cases of historical adaptation as analogs for future adaptation (e.g., Downing, 1996; Glantz, 1998; Meyer et al., 1998; Bryant et al., 2000). In general, these studies have found that adaptation comprises many incremental responses to multiple signals, and that extreme events are more likely to trigger adaptations than changes in average climate, just as they are more important determinants of impacts. Adaptation is more likely to occur in sectors controlled by markets, but markets provide less adaptation than would be optimal (Yohe et al., 1996; Schneider et al., 2000; Bryant et al., 2000; Tol et 
al., 1998). More such studies are needed, with particular focus on adaptations to past events that reasonably approximate projected future changes at appropriate scales. Related questions include how past and present climate regimes have influenced present institutions and practices, and how adaptation to present climate has shaped or limited resilience to potential future change. When extreme events such as floods, droughts, or storms occur, how have responses - e.g., decisions regarding rebuilding, compensation, and planning - affected resilience to future, perhaps greater extremes? Are there types of responses that appear to limit resilience and others that enhance it?

\subsection{ANALYSIS OF SPECIFIC ADAPTATION OPTIONS}

In addition to empirical studies of past adaptation, further work is needed to identify and assess specific measures for future adaptation. Like other recent assessments, the National Assessment identified many potential adaptation options to reduce climate impacts, but was unable to conduct systematic assessment of these options due to gaps in existing data and analysis (see, e.g., Smit et al., 2000; Reilly and Schimmelpfennig, 2000; Bryant et al., 2000). Present analyses of adaptation options are largely limited to taxonomy (e.g., UNEP 1998, Klein and Nicholls, 1999), with the exception of a few assessments of specific responses to sea-level rise (e.g., Mimura and Harasawa, 2000; Yohe and Schlesinger, 1998, Smith et al., 1998). Analyses of adaptation costs have largely been limited to autonomous, not planned adaptations (Tol and Fankhauser, 1997).

Several lines of work are needed to better identify and assess adaptation options. First, the extent of adaptive capacity in present infrastructure, technologies, institutions, and management practices must be examined. The design and management of specific present water-resource systems, for example, must be systematically re-examined under climate-change conditions, including potential regional-scale changes in variability and extreme events. Some of the research areas discussed above will help in this assessment of the adaptability of present systems. For example, examining the climate responses of additional crop cultivars is necessary for assessing how much adaptability agriculture derives from presently existing genetic diversity.

In addition, more systematic analyses of potential adaptation options are needed that consider their likely feasibility, cost, effectiveness, speed of implementation, acceptability to relevant stakeholders, and other beneficial and adverse effects. Options considered should include technological, managerial, informational, and institutional responses, with emphasis on those that promise to address the most acute vulnerabilities. Location-specific factors that may limit attempts to generalize responses should be considered. In addition to examining responses separately, potential combinations of multiple complementary adaptive responses should also be considered, particularly in view of the likelihood that resources will be simultaneously perturbed by multiple environmental stresses. In some cases, adaptation 
measures may be identified that are high priorities independent of climate change. In many cases, assembling data already available from dispersed sources may be all that is required (Smit et al., 1999). Options for which data are not available should be assessed through some combination of empirical studies of related technologies or practices, experimental pilot studies, and modeling. These analyses should proceed iteratively, with preliminary efforts to identify and catalog many potential options followed by more detailed assessment of those that appear most promising.

\section{Element 3: Climate Inputs for Impact Assessments}

Although the tightest constraints on the assessment came from limited knowledge of the responses of climate-sensitive systems, impact assessments also require continued improvements in the climatic information they use as inputs. Continuing scientific research is needed, to improve understanding of natural patterns of climate variation and projections of future climate change under human influences. Research to improve understanding of potential limits to climate predictability is also a crucial need, because some aspects of climate are likely to remain unpredictable on useful time scales. In addition, advancing impact assessment requires several areas of effort that are related to, but distinct from, climate-science research. These include more extensive replication, validation and intercomparison of existing models, and a concerted effort to develop, apply, and adapt climate models and data to meet the needs of impact studies.

\subsection{CLIMATE VARIABILITY AND EXTREME EVENTS}

Many climate impacts will depend more strongly on changes in climate variability - on time-scales ranging from extreme weather events to multi-year patterns of variation - than on changes in average climate, but the representation of variability and extreme events in present climate models is largely unexamined and probably weak. Some models have begun roughly to capture the behavior of the El Niño/Southern Oscillation (ENSO), and to suggest that greenhouse warming may change its regularity, frequency, and intensity, but better understanding of this relationship is needed (IRICP, 2000). Decadal-scale oscillations such as the North Atlantic Oscillation and the Pacific Decadal Oscillation are less well described, in part because few cycles are captured in the 100-year instrument record, and are not yet adequately reproduced in models. Further work is needed to better describe and understand these patterns of variability, and to learn how they might interact with anthropogenic climate change (NRC, 1995).

Present models also have limited ability to project changes in precipitation quantitatively or to project changes in storm paths and intensities. Future assessments will require better understanding of the factors controlling the frequency, intensity, and distribution of severe weather events such as heavy downpours, 
floods, hurricanes, and storm surges; of the character of meteorological events that produce severe flooding; and of potential interactions between long-term climate change, seasonal to inter-annual variability, and extreme events. Better representation of extreme weather events is especially important for understanding impacts on islands and in vulnerable coastal regions such as the southeastern states.

\subsection{HYDROLOGICAL PROCESSES AND CLIMATE-HYDROLOGY INTERACTIONS}

Many of the strongest climate impacts on ecosystems, agriculture, and freshwater availability and quality are driven by changes in hydrological variables such as soil moisture and runoff. Despite the importance of these processes, the factors that control them and their links to climate are inadequately understood. Uncertainties in model projections are larger for precipitation than for temperature, and larger still for soil moisture and runoff. For some U.S. regions, even the signs of likely changes in soil moisture and runoff are uncertain. The National Assessment conducted some of the first studies coupling climate-model projections to hydrological systems with the spatial detail needed to project changes in the magnitude, timing, and variability of streamflows in major river basins. These studies must be extended to add effects of changes in climate variability and land cover and management, and must be repeated for other river systems to develop specific projections of flood and shortage risks.

\subsection{REGIONAL-SCALE CLIMATE PROJECTIONS}

One important direction of continuing work in impact assessment, in the National Assessment and other recent assessments, is the coupling of climate projections to models of key climate-sensitive systems such as forests, freshwater, and urban air quality. Because these systems are controlled by processes operating at fine spatial scales, such coupling is presently limited by the coarse resolution of climate models. Improved assessments of impacts in domains controlled by such fine-scale processes will require further refinement of the scale of climate projections, using both statistical and model-based downscaling techniques. Such refinements of scale will also be important for improved assessment of climate impacts in metropolitan areas that incorporate fine-scale processes such as urban heat-island effects, and in regions whose climate is strongly shaped by abrupt topography, such as the Pacific Northwest.

\subsection{MULTIPLE CLIMATE AND EMISSION SCENARIOS}

Constrained computing resources severely limited the ability of the National Assessment to examine the effects of uncertainties in future emissions and climate: with a few exceptions, model-based analyses in the assessment were based on one emissions scenario, which was used to drive one run of each of two climate models. Obtaining robust and useful impact projections from models will require 
substantial expansion of the number and diversity of model runs available. For each climate model used, statistical ensembles of repeated runs will be needed to quantitatively describe its projections of climate variability, to identify which aspects of its projections are robust, and to explore potential limits to the predictability of future climate.

Assessments will also need model projections using multiple emission scenarios. Using a single emission scenario limits assessment in ways that will grow more serious as skill at characterizing ecological and socioeconomic impacts advances. It precludes consistent prioritization of uncertainties across the full scope of the climate issue, including uncertainties in future emissions. And it precludes the integrated consideration of impacts and measures to adapt to them with future emissions and measures to reduce them, which is essential for assessing the consequences of alternative levels of mitigation effort, of early versus later action, or of alternative atmospheric stabilization targets. For future assessments, multiple runs will be required of each climate model used, under a realistically wide range of emission and stabilization scenarios, to examine the resultant variation in projected impacts and vulnerabilities, and in the cost and effectiveness of adaptation measures.

\subsection{RECORDS OF PAST CHANGES IN REGIONAL CLIMATES}

Model-generated climate scenarios are only one way to examine potential climate impacts. Another valuable approach is to reconstruct regional records of past climate changes, variability, and extreme events, together with records of their forcing factors (e.g., greenhouse gases, solar variability, and volcanic eruptions) and their consequences. For the recent past (i.e., 100 to 150 years), such reconstructions can draw on analyses of instrumental records; for longer periods, they must rely on proxy climate data such as ice cores, tree rings, and corals (Mayewski et al., 1997). An increasingly rich set of paleoclimatic data is available to support reconstructions of past climatic conditions at global, hemispheric, and continental scales, but few reconstructions with fine temporal resolution yet exist at sub-continental scale.

Such reconstructions can provide more detailed descriptions of regional patterns of natural variability and extreme events than have yet been available. They can document natural rates of climate change, and together with reconstructions of past forcing factors can improve understanding of the sensitivity of the climate system and allow testing of climate-model projections under very different conditions from those of the present. By providing more detailed descriptions of past abrupt climate changes, such as the rapid changes over periods as short as a few years to a few decades that are observed in the ice-core record, they can help to identify the potential for future climate surprises. Finally, when combined with data at comparable scale on past distributions and characteristics of species and ecosystem types, such reconstructions can also provide valuable insights that are not otherwise available into the climate sensitivity and the rate and character of responses of ecosystems. 


\subsection{HIGH-QUALITY, LONG-TERM OBSERVATIONS}

The National Assessment was limited by the lack of continuous, long-term, qualitycontrolled observations of key climate and weather variables, and related physical, chemical, and ecological data. An enhanced capacity to generate and preserve such data and provide access to it will be essential to improving understanding of climate impacts. This will require extending the present instrumental record, with priority given to observations of variables that are critical for research on key factors controlling climate. The need for sustained, high-quality observations of variables with potentially large indirect climatic effects, such as atmospheric aerosols, is especially acute.

Making observations alone does not ensure that needed data are available and usable. Also required is a long-term commitment to maintaining and updating the observational capacity to keep measurements usable and relevant and to control biases, and to maintaining and supporting an archive that combines climatic and related hydrological and ecological data from multiple sources, e.g., routine operational systems, in-situ observations (including buoys and ships), space-based systems, and field research programs. Such an enhanced data and observation system would serve scientific research, assessment, and decision-making in multiple ways: by supporting characterization of climate variability, timely identification of trends, and early warning of emerging impacts; by helping to improve understanding of critical climate processes and regional climate impacts; and by supporting validation of climate models.

\subsection{A CLIMATE MODELING AND ANALYSIS CAPABILITY DEDICATED TO IMPACT STUDIES}

Making the multiple model runs required by impact assessments will require a substantial increase in available computational resources. An inadequacy of computational resources, in both hardware and software, is a broad constraint that presently limits U.S. Earth-science modeling (NRC, 1998). This constraint must be overcome to achieve significant progress in regional-scale climate projection and impact assessment. In addition, the National Assessment found that impact assessment requires various climate data that are distinct from the needs of climate sciences, in that they are more directly tied to specific decisions or vulnerabilities. Analyses of particular impacts or integration with models of climate-sensitive systems such as hydrology or forests may, for example, require daily weather data, better representation of extreme events, finer resolution projections, or different variables and statistical summaries than are normally saved in climate-model studies. Increasing confidence in impact studies will also require more extensive testing, replication, and comparison of climate models. While the ability of the two models used in the assessment to reproduce various aspects of the present climate was tested, more extensive tests at various scales could help refine the confidence attributed to specific aspects of their projections. Future assessments will also 
require experiments to elaborate and explain major differences between regional model projections. For example, while the Hadley and Canadian projections share many broad features, they diverge strongly for some variables in some regions, such as precipitation and soil moisture in the southeastern states. If such large disparities persisted between ensembles of multiple runs of each model, the causes of these differences would need to be explained. Examining the causes of such disparities would also allow better characterization of uncertainties in regional projections, and help advance modeling skill.

The needs of impact studies for such specialized climate services already exceed the existing capabilities of U.S. climate modeling centers. As methods of impact assessment develop further, these needs for specialized climate-data products and services are likely to grow and to diverge further from the capabilities of present climate-modeling centers and the data needs of the atmospheric-sciences community. This divergence suggests the need to develop a new kind of climate-modeling capacity, directed not to the refinement of modeling per se but to the application of first-rate modeling expertise to various forms of model-related investigations to support the needs of impact studies (e.g., UKDETR, 1997).

\section{Element 4: Development of Assessment Methods}

Assessment depends on scientific research, and assessments sometimes identify research priorities or even sponsor research that they identify as necessary. But assessment is a different activity from research: it serves different purposes, is judged according to different criteria, and requires different methods, processes, and skills to be done effectively. The purpose of assessment is not primarily to advance scientific knowledge, but rather to synthesize available knowledge to support decisions, whether by government officials or other actors, in pursuit of societal goals. The distinct purpose of assessment drives the differences in its methods, of which the two most basic concern appropriate evidentiary standards, and the role of prediction.

Scientific research uses a conservative evidentiary standard to control the assimilation of new claims, which is necessary to develop a stable and progressive body of validated knowledge. In assessment, this standard must be replaced by an approach that considers the relative costs of both types of error - rejecting true claims and accepting false ones - in view of the decisions that would likely be made based on each conclusion, and their consequences. The differences between science and assessment regarding the role of prediction are even more fundamental. In scientific research, successful prediction is the primary test of understanding. In assessment, understanding supports prediction. A major activity of assessment is to harness advances in understanding, such as now occurring in climate science, to support projection of valued environmental characteristics and how their evolution may vary under alternative assumptions about climate, socio-economic 
development, and relevant decisions. ${ }^{\star}$ But pervasive uncertainties and limitations to knowledge inevitably mean that projections of the detail, specificity, and confidence that decision-makers might desire usually cannot be provided. Making clear, practical statements that provide the best possible guidance for decisions that must be made, while appropriately representing the uncertainties inherent in present knowledge and the limits to predictive power that they imply, is the basic challenge of assessment. There is no general prescription for the best way to manage this challenge: how to do it in any instance will depend on the specifics of available knowledge and decision needs.

Developing better methods to manage this challenge is an additional area of work needed to advance assessments of climate impacts and vulnerabilities. The National Assessment identified several areas of weakness or immaturity in present assessment methods. These weaknesses impose limits on the effectiveness of present assessments that are different in character from the limits that arise from gaps in scientific knowledge, and which are unlikely to be resolved by progress in scientific knowledge alone. For improving future assessments, further development in these areas of assessment methods - through conceptual elaboration, small-scale pilot applications, and development of worked examples and expository materials - will be as important as further scientific research.

Moreover, since the merit of assessment methods is determined by their actual utility in decision and policy settings, empirical studies of the consequences and effectiveness of particular assessment activities and methods are also needed. These studies should seek to identify what processes, methods, and strategies have provided the most useful inputs to policy-makers under various conditions. In particular, they should examine how to design interactions between researchers and stakeholders in order to involve stakeholders in identifying and assessing key issues, risks, uncertainties, and potential responses, while also making effective use of advanced analytical methods (NRC, 1996).

\subsection{SOCIOECONOMIC SCENARIOS AND RELATED METHODS OF PROJECTION}

The fundamental questions of climate impact assessment - e.g., what are the likely impacts of climate change; what are the most acute vulnerabilities; what adaptation measures can reduce vulnerabilities, at what cost; and overall, how serious a concern is climate change - all concern what conditions are possible or likely in the future. Consequently, a central activity of assessment is making projections of future conditions: e.g., projecting changes in climate based on assumptions about emissions, and projecting impacts on systems of concern, based on assumptions about climate change. Such projections are inevitably uncertain, even speculative,

* Following usage adopted in the National Assessment and IPCC, a projection is a statement about the future that is explicitly conditional on assumed future evolution of boundary conditions such as emissions. Consequently, for decision-makers, a projection is '.. an indication of a possibility, and normally of one that could be influenced by their actions' (MacCracken, 2002). 
but are one necessary tool to provide the best advice current knowledge can offer to support decisions that must be made, by describing their potential consequences and associated risks and opportunities. Such projections also carry risks of misunderstanding, but the risks can be controlled through sustained efforts to convey the meaning, basis, and limits of the projections - clearly communicating their contingent and uncertain nature, the specific assumptions on which they are based, and the degree of confidence and consensus of the scientific knowledge underlying them.

The most common form of projection used in climate impact assessment involves assuming a set of future climate conditions (drawn from a climate model output or some other source) and modeling the resultant biophysical changes in ecosystems or resources, e.g., the effect on forest species mix or streamflow. This approach was largely followed, by necessity, in the National Assessment as in other recent assessments, and the research programs outlined above seek to advance this approach by learning more about the causal links from specified climate changes to responses of ecological and socio-economic systems.

This approach suffers from several limitations. The limitations that follow from using just one or a few climate scenarios are discussed in the previous section. A more basic limitation, however, is that the approach ignores the dependence of impacts on socio-economic conditions. Projecting changes in the state of resources or ecosystems provides only a small part of what is needed to characterize impacts on human societies and economies. Assessing these impacts requires understanding how people use and depend on specific aspects of their climate and environment, how they have adapted their practices and technologies to the climate they have experienced (including its variability), and how they do - and could - anticipate and respond to multiple dimensions of change in this environment. Consequently, a first step in making projections of impacts and vulnerabilities more realistic is to acknowledge their dependence on future socio-economic conditions as well as on climate, and to construct explicit scenarios of these conditions to use in parallel with climate scenarios. Like future climate, future socio-economic conditions are highly variable and uncertain, so the scenarios employed must span an appropriately broad range to represent this uncertainty. In principle, examining impacts under alternative scenarios of both climate and socioeconomic conditions can allow investigation of the relative sensitivity of key impacts to variation of climate and of socio-economic conditions, and to interactions between them.

Constructing socio-economic scenarios for impact assessment is, however, a much more complex and challenging problem than constructing either climate scenarios or scenarios of future emissions based on socioeconomic projections (IPCC, 2000). Emissions can be projected on the basis of a few national-level characteristics such as population, economic growth, and aggregate energy and carbon intensity of economic output. In contrast, the major socio-economic determinants of particular impacts may be highly local and non-obvious, and may interact strongly with other dimensions of environmental, economic, social, and 
technological change. Attempting to project potentially relevant socio-economic characteristics in all their detail - e.g., to describe fully the socio-economic factors that may influence the climatic vulnerability of wheat cultivation in eastern Washington State, of heat-stress deaths in Chicago, or of threatened coastal areas in Louisiana - can quickly become an impossibly complex and indefensibly arbitrary exercise. But the most common approach taken to avoid this problem, assuming explicitly or implicitly that present socioeconomic conditions will continue unchanged, is even less defensible.

The National Assessment invested considerable effort in pursuing a viable approach for constructing, comparing, and critiquing scenarios of relevant future socioeconomic conditions. The weak state of present knowledge created circularities in knowledge needs: projecting impacts and vulnerabilities required specifying future socioeconomic conditions; but determining which socioeconomic factors were the most important determinants of impacts in turn required doing multiple analyses of future impacts, to examine the contributions of many plausible factors. The assessment sought to overcome this roadblock through a hybrid procedure that was partly centralized, partly decentralized. A central team developed three alternative scenarios of a few socioeconomic variables (population and economic growth) judged likely to be important in all regions and sectors. Aggregate national scenarios of these few variables were then disaggregated among sub-national regions and sectors by using a regional economic model (Terleckyj, 1999). For elaboration of additional socioeconomic factors in specific regions and sectors, the central team made no further projections, but instead proposed a consistent template for region and sector analytic teams to develop their own projections. This approach sought to balance the need for national consistency of assumptions with deference to local and specialized expertise, and to encourage a diverse collection of partial, exploratory analyses from which an improved understanding of the socioeconomic determinants of impacts and vulnerability would be likely to emerge (Parson and Morgan, 1998).

Unfortunately, with a few exceptions the regional and sectoral analyses that comprised the National Assessment did not, or could not, use the proposed approach. Many of the analyses projected only biophysical impacts. Those that considered socioeconomic factors at all used only the aggregate projections of population and economic growth, or in some cases assumed continuation of baseline (i.e., present) conditions. None used the proposed template for identifying and projecting additional important socioeconomic characteristics. There were several reasons for this limited use of socioeconomic scenarios, including constrained time and resources, and insufficiently clear and timely communication of the proposed approach throughout the large, decentralized management structure of the assessment. In addition, many participants were reluctant to accept the wide range of uncertainties involved in socioeconomic projections, or to engage in projections that appeared speculative and so risked calling into question biophysical aspects of their analyses for which the confidence of projections appeared to be greater. 
A similar exercise in developing socioeconomic scenarios for climate impacts in the UK, which followed the IPCC approach in basing scenarios on narrative storylines rather than a common template for quantifying plausible ranges of key socioeconomic parameters, experienced a similar range of reactions by analysts and stakeholders (UKCIP, 1999).

Because of the limited use they made of socioeconomic scenarios, many of the analyses in the National Assessment excluded key factors likely to shape impacts and vulnerability. For example, it was not possible to consider the potential effects of population and economic growth on coastal development pressure, or on demand for water, forest, or agricultural products. These demand-side effects can reflect complex interactions between biophysical and socioeconomic processes, and can be important factors influencing vulnerabilities. Similarly, not considering scenarios of socioeconomic change made it impossible to consider effects of changes in population and demographic structure, settlement patterns, urban form and technology on heat stress or other health effects in urban areas.

More useful assessments of impacts and vulnerability will require more extensive use of socioeconomic scenarios and improved integration of socioeconomic with climatic and environmental scenarios (Lorenzoni et al., 2000; Berkhout and Hertin, 2000). Socioeconomic scenarios should be crafted to allow investigation of specific interactions between socio-economic and environmental change, and should be critically examined for consistency - both internally, and with assumed scenarios of emissions and environmental change. Because there is so much uncertainty about key processes and causal pathways that shape vulnerability and adaptive capacity, this work should adopt an exploratory, 'bootstrapping' character, by which the development of socioeconomic scenarios, theoretical and historical research to examine key determinants of vulnerability, and use of scenarios prospectively to assess potential future vulnerability, are iteratively conducted, critiqued, and revised in view of advancing knowledge and skill. A particular priority will be constructing scenarios with better representation of potential international linkages affecting vulnerability, through such mechanisms as movement of trade, capital, and people, international competition, shared use of resources, species migration, transfer of disease vectors, etc. Promising methods for consistent, integrated consideration of socioeconomic and climatic futures include integrated computer modeling, as well as various complementary methods such as judgmental integration of separate sectoral models, expert elicitation, policy exercises, scenario exercises, and simulation games (Parson and Fisher-Vanden, 1997; Rotmans and Dowlatabadi, 1998; Morgan et al., 1999; Morgan et al., 2001).

Such advances in the development, use, and integration of socioeconomic scenarios can substantially improve the practical utility of assessments' projections of impacts. But these projections, indeed any projections that reason forward along the causal chain from emissions to climate to impacts, will be limited by uncertainties in understanding of climatic, ecological, and socioeconomic processes. For example, projections that propagate reasonable uncertainty ranges at each step of 
the causal chain - emissions, climate response, and responses of ecological and social systems - can generate uncertainty ranges for final impacts that are so wide as to be uninformative; but artificially limiting upstream uncertainty by selecting one or a few paths through the multitude of possibilities risks being arbitrary; while focusing on aspects of the problem that are known with more confidence risks overlooking the most important impacts.

In the face of such limits to 'end to end' projections, assessments can usefully present other forms of statements to synthesize available knowledge. For example, assessments can uncouple uncertainties along the causal chain, constructing 'what-if' projections of the evolution of one part of the system contingent on reasonable and illustrative assumptions about the evolution of other parts. Rather than constructing projections of the whole system from emissions and their determinants through to impacts and their valuation, such uncoupled projections could examine how particular important resources or ecosystems might evolve based on specific assumptions about climate change; or how particular socioeconomic processes might evolve based on specific assumptions about changes in important resources or ecosystems. Such projections avoid the explosion of uncertainty by bounding the problem. By allowing examination of the sensitivity of each element of the system, they can help to identify and prioritize vulnerabilities, opportunities for intervention, or uncertainties for further investigation. When knowledge about potentially important impacts is insufficient even to conduct such truncated projections, assessments may simply list potential risks, vulnerabilities, or responses, or may seek to identify responses that appear robust to a wide range of uncertainties, or high-priority uncertainties for further investigation.

\subsection{METHODS TO ASSESS THRESHOLDS, BREAKPOINTS, AND VULNERABILITIES}

In the response of ecological and societal systems to climate change and other stresses, as in the climate system itself (Broecker 1987, 1997), rapid or discontinuous responses are possible when stresses exceed some threshold. Such responses are important to understand because they may be associated with acute vulnerabilities and are likely to pose strong challenges for adaptation (Schneider et al., 1998). Although such thresholds can readily be identified and explained once they have been crossed, they are difficult to identify or understand in advance, often because they are inadequately captured in models based on historical experience.

When there is concern about significant vulnerabilities, thresholds, or breakpoints, the limitations of scenario-based projections that reason forward from emissions to impacts may be most acute. Other logical structures for analyzing vulnerabilities appear more promising. For example, assessments can probe key vulnerabilities independent of any particular climate projection, by reasoning backward from impacts to climate rather than forward from climate to impacts. This approach would begin by identifying and describing major thresholds in the behav- 
ior of some system of concern that have the potential to cause grave harms. It would then reason backwards, asking what changes in climate would be likely to cause the specified impact, alone or together with other changes. For example, in assessing financial impacts of extreme weather events, one might investigate what combinations of climatic conditions and development patterns might bring losses so large as to risk insolvency of major re-insurers. Alternatively, one might ask what combinations of factors would so undermine the economic base of agriculturedependent Great Plains communities as to put them at risk of impoverishment or abandonment. Having identified the climatic conditions, or more likely the surface of alternative combinations of multiple changed conditions, that would seriously risk the specified severe impact, the analysis would then ask how likely such conditions are to occur under some specified emissions future. Reversing the causal order of the analysis in this way, from impacts to the climatic conditions likely to bring them rather than from climate to resultant impacts, focuses analytic effort efficiently on the risks of, and required conditions for, major impacts, rather than risking using effort inefficiently to find that many climate futures yield relatively modest impacts, without learning the limits of this result.

This assessment attempted to elaborate methods to identify and assess key thresholds and breakpoints, but these were not successfully implemented. Future assessments should continue this effort. Some examples of potential thresholds can be elaborated with only incremental advances in present knowledge and methods. For example, present ecosystem models already allow investigation of what combinations of changes in various climatic conditions would lead to large-scale replacement of a region's present predominant vegetation by other types. Similarly, some effects of sea-level rise, storm surge and erosion on coastal development or ecosystems have a discrete character that can permit analysis of the climate conditions likely to cause inundation of specific assets or loss of specific ecosystems. Other cases are likely to be much more complex, however, and to challenge existing scientific knowledge and methods. Still, given the high likelihood of continuing uncertainty in the specifics of regional-scale climate projections, these methods strongly merit further investigation and development. Persistent uncertainty also implies a high value to attempts to identify responses that are robust to key uncertainties, in that they perform well under a wide range of alternative future conditions.

\subsection{METhods To EVALUATE CHANGES IN CLIMATE, ECOSYSTEMS, AND RESOURCES}

The potential consequences of climate change differ in several fundamental ways from changes for which well-developed methods for evaluation and decisionmaking are available (Morgan et al., 1999). Climate change will simultaneously affect many resources and many diverse aspects of the natural, social, and economic environment, of which some are directly or indirectly represented in markets 
and others are not. Changes will be global in scope, but will vary strongly among affected locations and people, depending on many dimensions of the local environmental and socioeconomic context. Changes will extend decades or centuries into the future, and will consequently be experienced by people whose choices, perceptions, and values may differ strongly from ours. And finally, the changes will not necessarily be marginal and gradual, but may be large and in some cases sudden.

These conditions make the basis for evaluating potential effects of climate change, and tradeoffs with other valued conditions, deeply problematic. Many important dimensions of potential change are not adequately represented in markets. Equivalent monetized values for non-marketed environmental attributes may be estimated through contingent-valuation studies or other proxy valuation techniques (e.g., Costanza et al., 1997), but these efforts may also suffer from several serious limitations. For example, they may over-tax respondents' ability to visualize and evaluate hypothetical future environmental states, or may presume possibilities for substitution between different valued attributes that are not in fact present. Similarly, changes extending far into the future and affecting people and regions worldwide with vastly different cultures and states of development may render invalid conventional procedures for aggregating valuations across individuals, or for discounting future changes (Tol, 1997; Heal, 1997; Nordhaus, 1997). Finally, people's preferences and values may change over time or adjust in response to realized socioeconomic and environmental changes, thereby diverging from valuations that would be made from the perspective of the present.

Consequently, there is an urgent need for improved methods, both analytic and procedural, to elaborate tradeoffs and valuations of various aspects of climate, resources, and ecosystems, and the services they provide to society. This will require practical systems of metrics and indicators to track the status of ecosystems and the determinants of the services they provide, at both national and regional levels. It will also require improving existing methods to help individuals and groups identify, examine, and articulate their preferences, particularly regarding large, discontinuous environmental changes and uncertain outcomes. Development of such methods would be facilitated by resumed efforts to develop a satisfactory national accounting system that combines conventional measures of economic well-being with measures of the status of ecosystems and resources and the social costs of their unsustainable use.

\subsection{METHODS TO IDENTIFY, DESCRIBE, AND COMMUNICATE UNCERTAINTIES}

Processes of estimating, combining, and communicating uncertainties are central to conducting useful assessments. In communicating uncertainties, the National Assessment and the Third Assessment Report of the IPCC both represented substantial progress over earlier assessments. Each report adopted a standardized 
system of vocabulary to describe the confidence attributed to conclusions, which was explicitly linked to quantitative probability ranges in an attempt to ensure that uncertainties were expressed consistently (Moss and Schneider, 2000; NAST, 2000). While these are promising steps, the extent to which they improved readers' understanding of the conclusions and the usefulness of the assessments remains to be evaluated. Many other systems for expressing uncertainty are possible, of course, and future assessments would benefit from drawing more systematically on recent studies in cognitive psychology and risk communication to help improve the clarity with which both the assessments' conclusions and their limitations are communicated.

Communicating uncertainty is only one of the required functions of useful assessments, however. They must also be able to generate appropriate estimates of uncertainties in disparate domains, and consistently integrate knowledge of diverse origins and degrees of confidence. Estimation methods remain controversial, particularly regarding the combination of uncertainty estimates derived from different sources such as empirical evidence, analytical constructions, and subjective judgments, and the aggregation of multiple subjective probability judgments (Morgan and Henrion, 1990; Keith, 1996). Some integrated-assessment computer models have been used to construct ranges of plausible, internally consistent futures, and to aggregate and propagate uncertainties in order to provide rough, preliminary estimates of their relative likelihood (Prinn et al., 1999; Morgan and Dowlatabadi, 1996). In addition to identifying and prioritizing uncertainties, such models can be valuable for helping to identify decision strategies that are robust and adaptable under uncertainty.

\section{Conclusion: Toward an Integrated Regional Capacity for Environmental Research, Applications, and Assessment}

Substantial recent progress in assessment has been principally driven by progress in climate science. While further progress in climate science will continue to advance assessment capability, better understanding is even more urgently needed of the climate-related responses of biophysical and human systems, of linkages between different impacts and systems, and of potential responses and their consequences - areas that thus far have received less attention than climate science. To demand precise, confident small-scale climate projections before pursuing an intensive program to understand climate impacts, vulnerabilities, and responses, would be a serious error. Such delay would risk missing opportunities to anticipate and ameliorate climate impacts, subjecting society to significant and avoidable risks. The likelihood that significant uncertainties will remain in regional climate projections despite continuing climate research and improvement of models reinforces this conclusion. Indeed, pervasive continuing uncertainty is sufficiently likely in climatic, ecological, and socioeconomic domains that assessment must 
embrace uncertainty. Assessments must not be limited to projecting impacts and vulnerabilities contingent on specified climate projections. Rather, they should explore impacts and vulnerabilities under a wide range of rates and magnitudes of climate change and other environmental and socioeconomic conditions; they should also start with serious impacts, seeking to distinguish changes that lie within systems' ranges of adaptability from those likely to bring severe harm, and reason backwards to identify the climatic conditions that could produce such outcomes; and they should seek to identify and assess specific responses that are robust in the face of these uncertain futures and adaptable as our understanding advances (NRC, 1999a).

To date, efforts to observe, model, and assess climate change and other environmental stresses have principally taken a global perspective. These efforts have yielded some results of great value, such as satellite datasets for some variables that provide both global coverage and fine enough resolution to use at local scales. It is becoming clear, however, that global-scale activities - whether in observing systems, data systems, or modeling - face both scientific and management challenges that limit their ability to provide information of the detail and quality needed to understand and manage multiple environmental stresses and their impacts at local, regional, and national scales. Instead, the next generation of additional efforts should focus principally on specific, coherently defined regions, typically with a linear scale of order $10^{3}$ kilometers. In the United States, such regions would be sub-national or in some cases bi-national with Canada or Mexico; elsewhere in the world, they might involve coordination across several national boundaries.

Such regional efforts might integrate multiple kinds of research, analytic, and assessment activity, initially as pilot projects where scientific and institutional conditions were favorable. These regional efforts would integrate observations, data and information systems, process studies, and models. They would seek to advance integrated understanding of linked environmental systems and stresses in the region, with both the process detail and spatial resolution necessary to inform regional decision needs. The initiatives would seek to link existing observing systems into integrated webs of multiple, co-located sensors, by building co-operative agreements between the relatively manageable set of federal, state, and local agencies involved. They would also develop integrated, widely accessible regional data and information systems, establishing partnerships with multiple public and private stakeholders to identify diverse uses for the data, test the system's tractability, and pursue concrete regional benefits. This integrated approach would likely generate better quality, more useful, and less costly observations than the present suite of disconnected, separately funded systems, and would also support federal and state mandates to ensure that research investments yield maximum societal benefit and to make data useful to the public. The limited spatial scope of these initiatives would control the scientific, informational, and organizational complexity they faced in attempting to understand and assess linked regional impacts of multiple environmental stresses. Dealing with a manageable number of institutions and 
stakeholders, they would focus on regional-scale resources, processes, issues, and management decisions, drawing on larger-scale data or models as necessary to represent important external forcings on regional conditions or to establish boundary conditions (NRC, 1999a).

Developing a capability for modeling, forecasting, and projection would be central to the work of these regional activities. Recent decades have seen vast increases in ability to forecast weather and climate on daily to seasonal scales, and a growing demand for additional forecasting capabilities that integrate knowledge of physical, chemical, biological, and human systems - e.g., forecasts of air quality, energy demand, water quality and quantity, and ultraviolet radiation - that will further grow with the need to assess increasing environmental stresses, associated impacts, and potential responses. Weather and climate models can provide the core for a broader regional environmental modeling capability, which can be linked to models of air quality, river flows, ecosystems, and other variables. Just as mesoscale models are increasingly central to weather and climate studies because of their forecasting abilities on the scale of synoptic weather systems and regional human endeavors, an integrated mesoscale modeling capability - linked to regional sensor webs and information systems - could support experimental forecasts and longerterm projections of new variables, helping to advance both scientific knowledge and the assessment of impacts and responses. The mandate to inform multiple regional stakeholders' decisions, through forecasts and other means, would provide structure and discipline to the activities: the modeling framework would support rapid assimilation of new data from observations and process studies, while subsequent evaluation of model-based forecasts would provide feedback to improve data and models and to identify priority areas for process studies. The integration of research and operational functions would likely benefit both, simultaneously advancing operational forecasting capability, improving the characterization of uncertainties, providing a compelling scientific framework to motivate the integration of new observations, and stimulating research. Other forms of assessment such as vulnerability analyses, evaluation of specific adaptation options, and searching for robust responses, would complement the analyses based on forecasting and projections.

Pursuing such integration of research, applications, and assessment initially at modest regional scales would offer several advantages over attempting similar integration at larger scales. A regional approach can better take account of region-specific resources, vulnerabilities, management priorities, and adaptation options; can more effectively develop appropriate socioeconomic scenarios of the required level of detail; and can draw on fine-grained regional data and knowledge. Perhaps most importantly, this regional approach could advance the assessment and implementation of adaptation options, by promoting sustained relationships with resource managers, industry experts, and other local stakeholders. These are the people whose decisions must take account of climate change and other environmental stresses, who hold the specialized practical knowledge needed to 
evaluate adaptation options, and who are the primary source of the technological and managerial initiatives needed to implement them. Results and insights from these regional efforts could be aggregated to national scale, to synthesize results of national significance and to support integrated national policy-making on mitigation and adaptation. Moreover, demonstration of benefits from initial regional pilot efforts would likely generate interest in replicating them with linked activities in other regions, possibly helping to advance the long frustrated goal of integrated national and global observing systems.

In conclusion, the program of work proposed here to advance assessment capability is not just one of scientific research. Rather, it embraces a collection of activities to generate, integrate, and assess knowledge relevant to climate, other stresses, and associated impacts and vulnerabilities, in order to support and inform societal choice. The program will require broad-based partnerships between scientists, resource managers, officials, and other stakeholders, in order to define and prioritize key issues, characterize relevant uncertainties, gather the breadth of knowledge needed to understand how climate variability and change interact with management practices, and assess potential responses. The approach we propose will pose novel substantive and organizational challenges, but the experience of the National Assessment suggests that such an approach holds the best promise of advancing society's capacity to manage adaptively under a changing climate, in view of changing knowledge, technology, and public values.

\section{References}

Adger, W. N. and Kelly, P. M.: 1999, 'Social Vulnerability to Climate Change and the Architecture of Entitlements', Mitigation Adaptation Strategies Global Change 4, 253-266.

Alberto, A. M. P., Ziska, L. H., Cervancia, C. R., and Manalo, P. A.: 1996, 'The Influence of Increasing Carbon Dioxide and Temperature on Competitive Interactions between a $\mathrm{C}_{3}$ Crop, Rice (Oryza sativa), and a $\mathrm{C}_{4}$ Weed (Echinochloa glabrescens)', Aust. J. Plant Physiol. 23, 795-802.

Ayres, M. P. and Lombardero, M. J.: 2000, 'Assessing the Consequences of Global Change for Forest Disturbance from Herbivores and Pathogens', Sci. Total Environ. 26, 263-286.

Berkhout, F. and Hertin, J.: 2000, 'Socio-Economic Scenarios for Climate Impact Assessment', Global Environ. Chang 10, 165-168.

Boer, G. J., Flato, G. M., and Ramsden, D.: 1999b, 'A Transient Climate Change Simulation with Historical and Projected Greenhouse Gas and Aerosol Forcing: Projected Climate for the 21st Century', Clim. Dyn. 16, 427-450.

Boer, G. J., Flato, G. M., Reader, M. C., and Ramsden, D.: 1999a, 'A Transient Climate Change Simulation with Historical and Projected Greenhouse Gas and Aerosol Forcing: Experimental Design and Comparison with the Instrumental Record for the 20th Century', Clim. Dyn. 16, 405-426.

Bohle, H. G., Downing, T. E., and Watts, M. J.: 1994, 'Climate Change and Social Vulnerability: Toward a Sociology and Geography of Food Insecurity', Global Environ. Change 4, 37-48.

Broecker, W. S.: 1987, 'Unpleasant Surprises in the Greenhouse', Nature 328, 123-126.

Broecker, W. S: 1997, 'Thermohaline Circulation, the Achilles Heel of our Climate System: Will Manmade $\mathrm{CO}_{2}$ Upset the Current Balance?', Science 278, 1582-1588. 
Bryant, C. R., Smit, B., Brklacich, M., Johnston, T. R., Smithers, J., Chiotti, Q., and Singh, B.: 2000, 'Adaptation in Canadian Agriculture to Climatic Variability and Change', Clim. Change 45, 181-201.

Clark, G. E., Moser, S. C., Ratick, S. J., Dow, K., Meyer, W. B., Emani, S., Jin, W., Kasperson, J. X., Iasperson, R.K, and Schwarz, H. E.: 1998, 'Assessing the Vulnerability of Coastal Communities to Extreme Storms: The Case of Revere, MA, U.S.A.', Mitigation Adaptation Strategies Global Change 3, 59-82.

Clark, W. C., Jaeger, J., Corell, R., Kasperson, R., McCarthy, J. J., Cash, D., Cohen, S. J., Desanker, P., Dickson, N. M., Epsteon, P., Guston, D. H., Hall, J. M., Jaeger, C., Janetos, A., Leary, N., Levy, M. A., Luers, A., MacCracken, M., Melillo, J., Moss, R., Nigg, J. M., Parry, M. L., Parson, E.A., Ribot, J. C., Schellnhuber, H.-J., Schrag, D. P., Seilestad, G. A., Shea, E., Vogel, C., and Wilbanks, T. J.: 2000, 'Assessing Vulnerability to Global Environmental Risks', Report of the Workshop on Vulnerability to Global Environmental Change: Challenges for Research, Assessment and Decision Making. May 22-25, 2000, Airlie House, Warrenton, Virginia. BCSIA Discussion Paper 2000-12, Environment and Natural Resources Program, Belfer Center for Science and International Affairs, Kennedy School of Government, Harvard University.

Conroy, J. P., Seneweera, S., Basra, A. S., Roger, G., and Nissenwooler, B.: 1994, 'Influence of Rising Atmospheric $\mathrm{CO}_{2}$ Temperature on Growth, Yield, and Grain Quality of Cereal Crops', Aust. J. Plant. Physiol. 21, 741-758.

Costanza, R., d'Arge, R., de Groot, R., Farber, S., Grasso, M., Hannon, B., Limburg, K., Naeem, S., O'Neill, R., Paruelo, J., Raskin, R., Sutton, P., and van den Belt, M.: 1997, 'The Value of the World's Ecosystem Services and Natural Capital', Nature 387, 259.

Cramer, W., Shugart, H. H., Noble, I. R., Woodward, F. I., Bugmann, H., Bondeau, A., Foley, J. A., Gardner, R. H., Lauenroth, W. K., Pitelka, L. F., and Sutherst, R. W.: 1999, 'Ecosystem Composition and Structure', in Walker, B., Steffen, W., Canadell, J., and Ingram, J. (eds.), The Terrestrial Biosphere and Global Change, Implications for Natural and Managed Ecosystems, Cambridge University Press, Cambridge, pp. 190-228.

Cutter, S. L.: 1996, 'Vulnerability to Environmental Hazards', Prog. Hum. Geog. 20, 529-539.

Downing, T. E. (ed.): 1996, Climate Change and World Food Security, Springer, Berlin, 662 pp.

Downing, T. E., Butterfield, R., Cohen, S., Huq, S., Moss, R., Rahman, A., Sokona, Y., and Stephen, L.: 2000, 'Climate Change Vulnerability: Toward a Framework for Understanding Adaptability to Climate Change Impacts', Report to the United Nations Environment Programme, Environmental Change Institute, Oxford University.

Duke, J. S. and Mooney, H. A.: 1999, 'Does Global Change Increase the Success of Biological Invaders?', Trends in Ecology and Evolution 14, 135-139.

Easterling, W. E., Crosson, P. R., Rosenberg, N. J., McKenney, M. S., Katz, L.A., and Lemon, K. M.: 1993, 'Agricultural Impacts of and Responses to Climate Change in the Missouri-Iowa-NebraskaKansas (MINK) Region', Clim. Change 24, 23-61.

Glantz, M. H. (ed.): 1998 Societal Responses to Regional Climatic Change: Forecasting by Analogy. Westview Press, Boulder.

Gregory, P. J., Ingram, J. S. I., Campbell, B., Goudriaan, J., Hunt, L. A., Landsberg, J. J., Linder, S., Stafford Smith, M., Sutherst, R. W., and Valentin, C.: 1999, 'Managed Production Systems', in Walker, B., Steffen, W., Canadell, J., and Ingram, J. (eds.), The Terrestrial Biosphere and Global Change, Implications for Natural and Managed Ecosystems, Cambridge University Press, Cambridge, pp. 229-270.

Heal, G.: 1997, 'Discounting and Climate Change', Clim. Change 37, 335-343.

IPCC (Intergovernmental Panel on Climate Change): 2000, Emissions Scenarios, Special Report of Working Group III, Cambridge University Press, New York.

IPCC (Intergovernmental Panel on Climate Change): 2001a, Climate Change 2001: The Scientific Basis, Third Assessment Report of Working Group I, Cambridge University Press, New York. 
IPCC (Intergovernmental Panel on Climate Change): 2001b, Climate Change 2001: Impacts, Adaptation, and Vulnerability, Third Assessment Report of Working Group II, Cambridge University Press, New York.

IRICP (International Research Institute for Climate Prediction): 2000, 'Recent Information and References on El Nino Prediction', Available at http://iri.ucsd.edu/forecast.

Johns T. C., Carnell, R. E., Crossley, J. F., Gregory, J. M., Mitchell, J. F. B., Senior, C. A., Tett, S. F. B., and Wood, R. A.: 1997, 'The Second Hadley Centre Coupled Ocean-Atmosphere GCM: Model Description, Spinup, and Validation', Clim. Dyn. 13, 103-134.

Kasperson, R. E., Kasperson, J. X., Turner II, B. L., Dow, K., and Meyer, W. B.: 1995, 'Critical Environmental Regions: Concepts, Distinctions, and Issues', in Kasperson, J. X., Kasperson, R. E., and Turner II, B. L. (eds.), Regions at Risk: Comparisons of Threatened Environments, United Nations University Press, New York, pp. 1-41.

Kane, S. and Yohe, G.: 2000, 'Societal Adaptation to Climate Variability and Change: An Introduction', Clim. Change 45, 1-4.

Kates, R. W., Ausubel, J. H., and Berberian, M. (eds.): 1985. Climate Impact Assessment: Studies of the Impact of Climate and Society, John Wiley, Chichester, U.K.

Keith, D. W.: 1996, 'When is it Appropriate to Combine Expert Judgments?', Clim. Change 33, 139-144.

Kelly, P. and Adger, W. N.: 2000, 'Theory and Practice in Assessing Vulnerability to Climate Change and Facilitating Adaptation', Clim. Change 47, 325-352.

Klein, R. J. T. and Nicholls, R. J.: 1999, 'Assessment of Coastal Vulnerability to Climate Change', Ambio 28, 182-187.

Körner, C., Bazzaz, F. A., and Field, C. B.: 1996, 'The Significance of Biological Variation, Organism Interactions, and Life Histories in $\mathrm{CO}_{2}$ Research', in Körner, C. and Bazzaz, F. A. (eds.), Carbon Dioxide, Populations, and Communities, Academic Press, San Diego, pp. 443-456.

Lincoln D. E., Fajer, E. D., and Johnson, R. H.: 1993. 'Plant-Insect Herbivore Interactions in Elevated $\mathrm{CO}_{2}$ Environments', Trends in Ecology and Evolution 8, 64-68.

Lorenzoni, I., Jordan, A., Hulme, M., Turner, R. K., and O'Riordan, T.: 2000, 'A Co-Evolutionary Approach to Climate Change Impact Assessment: Part 1, Integrating Socio-Economic and Climate Change Scenarios', Global Environ. Change 10, 57-68.

MacCracken, M. C.: 2002, 'Do the Uncertainty Ranges in the IPCC and U.S. National Assessments Account Adequately for Possibly Overlooked Climatic Influences?', Clim. Change 52, 13-23.

Mack, M. C. and D'Antonio, C. M.: 1998, 'Impacts of Biological Invasions on Disturbance Regimes', Trends Ecol. Evol. 13, 195-198.

Matsui T., Namuco, O. S., Ziska L. H., and Horie, T.: 1997, 'Effects of High Temperature and $\mathrm{CO}_{2}$ Concentration on Spikelet Sterility in Indica Rice', Field Crop. Res. 51, 213-219.

Mayewski, P. A., Meeker, L. D., Twickler, M. S., Whitlow, S., Yang, Q. Z., Lyons, W. B., and Prentice, M.: 1997, 'Major Features and Forcing of High-Latitude Northern Hemisphere Atmospheric Circulation using a 110000 Year-Long Glaciochemical Series', J. Geophysical. Res. Oceans 102, 345-366.

Maxwell, B., Mayer, N., and Street, R.: 1997, The Canada Country Study: Climate Impacts and Adaptation, Environmental Adaptation Research Group, Environment Canada, Downsview, Ontario.

Mendelsohn, R., Nordhaus, W. D., and Shaw, D.: 1994, 'The Impact of Global Warming on Agriculture: A Ricardian Analysis', Am. Econ. Rev. 84, 753-771.

Meyer, W. B., Butzer, K. W., Downing, T. E., Turner II, B. L., Wenzel, G. W., and Wescoat, J. L.: 1998, 'Reasoning by Analogy', in Rayner, S. and Malone, E. L. (eds.), Human Choice and Climate Change, Vol. 3: Tools for Analysis, Battle Press, Columbus, Ohio, pp. 217-289.

Miller, K. A., Rhodes, S. L., and MacDonnell, L. J.: 1997, 'Water Allocation in a Changing Climate: Institutions and Adaptation', Clim. Change 35, 157-177. 
Mimura, N. and Harasawa, H. (eds.): 2000, Data Book of Sea-Level Rise, 2000, Centre for Global Environmental Research, National Institute for Environmental Studies, Environment Agency of Japan, Ibaraki, 280 pp.

Mitchell J. F. B., Johns, T. C., Gregory, J. M., and Tett, S.: 'Climate Response to Increasing Levels of Greenhouse Gases and Sulphate Aerosols', Nature 376, 501-504.

Morgan, M. G. and Dowlatabadi, H.: 1996, 'Learning from Integrated Assessment of Climate Change', Clim. Change 34, 337-368.

Morgan, M. G. and Henrion, M.: 1990, Uncertainty: A Guide to Dealing with Uncertainty in Quantitative Risk and Policy Analysis, Cambridge University Press, New York.

Morgan, M. G., Kandlikar, M., Risbey, J., and Dowlatabadi, H.: 1999, 'Why Conventional Tools for Policy Analysis Are often Inadequate for Problems of Global Change', Clim. Change 41, 271-281.

Morgan, M. G., Pitelka, L., and Shevliakova, E.: 2001, 'Elicitation of Expert Judgments of Climate Change Impacts on Forest Ecosystems', Clim. Change 49, 279-307.

Moss, R. H. and Schneider, S. H.: 2000, 'Uncertainties in the IPCC TAR: Recommendations to Lead Authors for more Consistent Assessment and Reporting', in Pachauri, R., Taniguchi, T., and Tanaka, K. (eds.), Guidance Papers on Cross-Cutting Issues in the Third Assessment Report of the IPCC, Inter-governmental Panel on Climate Change, Geneva, pp. 33-51. Available at www.gispri.or.jp.

NAST (National Assessment Synthesis Team): 2000, Climate Change Impacts on the United States: The Potential Consequences of Climate Variability and Change. Overview, Cambridge University Press, Cambridge, U.K.

NAST (National Assessment Synthesis Team): 2001, Climate Change Impacts on the United States: The Potential Consequences of Climate Variability and Change. Foundation, Cambridge University Press, Cambridge, U.K.

Nordhaus, W. D.: 1997, 'Discounting in Economics and Climate Change', Clim. Change 37, 315328.

NRC (National Research Council), Climate Research Committee: 1995, Natural Climate Variability on Decade-to-Century Time Scales, National Academy Press, Washington D.C.

NRC (National Research Council), Committee on Risk Characterization: 1996, Understanding Risk: Informing Decisions in a Democratic Society, National Academy Press, Washington D.C.

NRC (National Research Council), Climate Research Committee: 1998, Capacity of U.S. Climate Modeling to Support Climate Change Assessment Activities, National Academy Press, Washington, D.C.

NRC (National Research Council), Board on Sustainable Development: 1999a, Our Common Journey: A Transition toward Sustainability, National Academy Press, Washington D.C.

NRC (National Research Council), Committee on Global Change Research: 1999b, Global Environmental Change, Research Pathways for the Next Decade, National Academy Press, Washington D.C.

NRC (National Research Council), Panel on the Human Dimensions of Seasonal-to-Interannual Climate Variability: 1999c, Making Climate Forecasts Matter, National Academy Press, Washington D.C.

Parry, M. and Livermore, M. (eds.): 1999, 'A New Assessment of the Global Effects of Climate Change', Global Environ. Change 9, Supp.

Parson, E. A. and Fisher-Vanden, K.: 1997, 'Integrated Assessment Models of Global Climate Change', Ann. Rev. Energ. Env. 22, 589-628.

Parson, E. A. and Morgan, M. G.: 1998, 'Guidance to Regional and Sectoral Teams for Analizing Socio-Economic and Ecological Impacts', National Assessment Synthesis Team, U.S. Global Change Research Program. April 23, 1998. Washington, D.C.

Patterson, D. T.: 1995, 'Weeds in a Changing Climate', Weed Sci. 43, 685-701. 
Patterson, D. T., Westbrook, J. K., Joyce, R. J. V., Lingren, P. D., and Rogasik, J.: 1999, 'Weeds, Insects, and Diseases', Clim. Change 43, 711-727.

PCAST (President's Committee of Advisors on Science and Technology): 1997, Federal Energy Research and Development for the Challenges of the 21 st Century, Report of the Energy Research and Development Panel, Washington D.C.

Petschel-Held, G., Block, A., Cassel-Gintz, M., Kropp, J., Ludeke, M. K. B., Moldenhauer, O., Reusswig, F., and Schellnhuber, H. J.: 1999, 'Syndromes of Global Change: A Qualitative Modeling Approach to Assist Global Environmental Management', Environ. Model. Assess. 4, 195-314.

Prinn, R., Jacoby, H., Sokolov, A., Wang, C., Xiao, X., Yang, Z., Eckhaus, R., Stone, P., Ellerman, D., Melillo, J., Fitzmaurice, J., Kicklighter, D., Holian, G., and Liu, Y.: 1999, 'Integrated Global System Model for Climate Policy Assessment: Feedbacks and Sensitivity Studies', Clim. Change 41, 469-546.

Reilly, J., Hohmann, N., and Kane, S.: 1994, 'Climate Change and Agricultural Trade: Who Benefits, Who Loses?' Global Environ. Change 4, 24-36.

Reilly, J. and Schimmelpfennig, D.: 2000, 'Irreversibility, Uncertainty, and Learning: Portrait of Adaptation to Long-Term Climate Change', Clim. Change 45, 253-278.

Ribot, J. C.: 1995, 'The Causal Structure of Vulnerability: Its Application to Climate Impact Analysis', GeoJournal 35, 119-122.

Ribot, J. C., Najam, A., and Watson, G.: 1996, 'Climate Variation, Vulnerability and Sustainable Development in the Semi-arid Tropics', in Ribot, J. C., Magalhães, A. R., and Panagides, S. S. (eds.), Climate Variability, Climate Change and Social Vulnerability in the Semi-arid Tropics, Cambridge University Press, Cambridge, pp. 13-54.

Risbey, J., Kandlikar, M., Dowlatabadi, H., and Graetz, D.: 1999, 'Scale, Context, and Decision Making in Agricultural Adaptation to Climate Variability and Change', Mitigation Adaptation Strategies Global Change 4, 137-165.

Rosenberg, N. and Crosson, P.: 1993, 'An Overview of the MINK Study', Clim. Change 24, 159-173.

Rosenzweig, C. and Parry, M.: 1994, 'Potential Impacts of Climate Change on World Food Supply', Nature 367, 133-139.

Rotmans, J. and Dowlatabadi, H.: 1998, 'Integrated Assessment Modeling', in Rayner, S., and Malone, E. L. (eds.), Human Choice and Climate Change: An International Assessment, Vol. 3, 'Tools for Policy Analysis', Chapter 5, Battelle Press, Columbus, OH.

Sala, O. E., Chapin III, F. S., Gardner, R. H., Lauenroth, W. K., Mooney, H. A., and Ramakrishnan, P. S.: 1999, 'Global Change, Biodiversity and Ecological Complexity', in Walker, B., Steffen, W., Canadell, J., and Ingram, J., (eds.), The Terrestrial Biosphere and Global Change, Implications for natural and managed ecosystems, Cambridge University Press, Cambridge, pp. 304-328.

Schneider, S. H., Easterling, W. E., and Mearns, L. O.: 2000, 'Adaptation: Sensitivity to Natural Variability, Agent Assumptions and Dynamic Climate Changes', Clim. Change 45, 203-221.

Schneider, S. H., Turner II, B. L., and Garriga, H. M.: 1997, 'Imaginable Surprise in Global Change Science', J. Risk Res. 1, 165-185.

Sen, A. K.: 1990, 'Food, Economics, and Entitlements', in Dreze, J. and Sen, A. K. (eds.), The Political Economy of Hunger, Vol. 1., Clarendon, Oxford, pp. 34-52.

Smit, B., Burton, I., Klein, R. J. T., and Street, R.: 1999, 'The Science of Adaptation: A Framework for Assessment', Mitigation Adaptation Strategies Global Change 4, 199-213.

Smit, B., Burton, I., Klein, R. J. T., and Wandel, J.: 2000, 'An Anatomy of Adaptation to Climate Change and Climate Variability', Clim. Change 45, 225-251.

Smith, J. B., Tol, R. S. J., Ragland, S., and Fankhauser, S.: 1998, 'Proactive Adaptations to Climate Change: Three Case Studies on Infrastructure Investments', IVM Discussion Paper D98/03.

Terleckyj, N. E.: 1999, 'Analytic Documentation of Three Alternate Socioeconomic Projections, 1997-2050’, NPA Data Services, Inc., Washington D.C. 
Tol, R. S. J.: 1997, 'The Social Cost Controversy', in Sors, A., Liberatore, A., Funtowicz, S., Hourcade, J. C., and Fellous, J. L. (eds.), Prospects for Integrated Environmental Assessment: Proceedings of the International Symposium, DG-11, European Commission.

Tol, R. S. J. and Fankhauser, S.: 1997, 'On the Representation of Impact in Integrated Assessment Models of Climate Change', Environ. Model. Assess. 3, 63-74.

Tol, R. S. J., Fankhauser, S., and Smith, J. B.: 1998, 'The Scope for Adaptation to Climate Change: What Can We Learn from the Impact Literature?', Global Environ. Change 8, 109-123.

Tol, R. S. J., van der Grijp, N. M, Olsthoorn, A. A., and van der Werff, P. E.: 1999, Adapting to Climate Change: A Case Study on Riverine Flood Risks in the Netherlands, SIRCH Working Paper 5, Institute for Environmental Studies, Free University, Amsterdam.

UKCIP (U.K. Climate Impacts Programme): 1999, 'Socio-Economic Future Scenarios for Climate Impact Assessment: Final Report', Science and Technology Policy Research.

UKCIP (U.K. Climate Impacts Programme): 2000, Climate change: Assessing the Impacts - Identifying Responses. The First Three Years of the UK Climate Impacts Programme, U.K. Department of the Environment, Transport, and the Regions.

UKDETR (U.K. Department of the Environment, Transport, and the Regions): 1997, 'The Climate Impacts LINK Project: Applying Results from the Hadley Centre's Climate Change Experiments for Climate Change Impacts Assessments', Climatic Research Unit, University of East Anglia, Norwich.

UNEP, Feenstra, J., Burton, I., Smith, J., and Tol, R. (eds.): 1998, Handbook on Methods for Climate Impact Assessment and Adaptation, Strategies United Nations Environment Programme and Institute for Environmental Studies, Free University, Amsterdam.

Vitousek, P. M., Mooney, H. A., Lubchenco J., and Melillo, J. M.: 1997, 'Human Domination of Earth's Ecosystems', Science 277, 494-499.

Volney, W., and Jan, A.: 1996, 'Climate Change and Management of Insect Defoliators in Boreal Forest Ecosystems', in Apps, M. J. and Price, D. T. (eds.), Forest Ecosystems, Forest Management, and the Global Carbon Cycle, NATO ASI Series, Vol. I 40, Springer-Verlag, Berlin, pp. 79-88.

Woodward, F. I.: 1987, Climate and Plant Distribution, Cambridge University Press, New York.

Yohe, G., Neumann, J., Marshall, P., and Ameden, H.: 1996, 'The Economic Cost of GreenhouseInduced Sea-Level Rise for Developed Property in the United States', Clim. Change 32, 387-410.

Yohe, G. and Schlesinger, M.: 1998, 'Sea-Level Change: The Expected Economic Cost of Protection or Abandonment in the United States', Clim. Change, 38, 437-472.

Ziska, L. H.: 2000, 'The Impact of Elevated $\mathrm{CO}_{2}$ on Yield Loss from a $\mathrm{C}_{3}$ and $\mathrm{C}_{4}$ Weed in FieldGrown Soybean', Glob. Change Biol. 6, 1-7.

Ziska, L. H. and Bunce, J. A.: 1997, 'Influence of Increasing Carbon Dioxide Concentration on the Photosynthetic and Growth Stimulation of Selected $\mathrm{C}_{4}$ Crops and Weeds', Photosynth. Res. 54, 199-208.

Ziska, L. H. and Caulfield, F. A.: 2000, 'Rising $\mathrm{CO}_{2}$ and Pollen Production of Common Ragweed (Ambrosia artemisiifolia L.), A Known Allergy-Inducing Species: Implications for Public Health', Aust. J. Plant Physiol. 27, 10.

Ziska, L. H. and Manalo, P. A.: 1996, 'Increasing Night Temperature Can Reduce Seed Set and Potential Yield of Tropical Rice', Aust. J. Plant Physiol. 23, 791-794.

Ziska, L. H. and Teasdale, J. R.: 2000, 'Sustained Growth and Increased Tolerance to Glyphosate Observed in a $\mathrm{C}_{3}$ Perennial Weed, Quackgrass (Elytrigia repens), Grown at Elevated Carbon Dioxide', Aust. J. Plant Physiol. 27, 159-166.

(Received 8 November 2000; in revised form 2 May 2002) 